\title{
The Accuracy of Lay Estimates of Abortion Rates and the Demographic, Attitudinal, and Behavioral Sources of Variation in these Estimates
}

\author{
Eric Beasley, $\mathrm{PhD}$ \\ Michigan State University \\ Dilshani Sarathchandra, $\mathrm{PhD}$ \\ University of Idaho
}

* Please address correspondence to Eric Beasley, Office of the Associate Provost for Undergraduate Education, Michigan State University, East Lansing, MI 48824. Email: beasle23@msu.edu.

\begin{abstract}
Abortion is a topic and practice with deep socio-political undergirding. While research on attitudes toward abortions is prevalent, less is known about perceptions of the frequency of abortion in the general population. Using primary data gathered from an online survey of students, faculty and staff of two public universities in the U.S., we found that people generally underestimate the percentage of pregnancies that end in abortion. We discuss this finding and the role of demographic, attitudinal, and behavioral variables in the abortion estimates made by respondents. Additionally, we discuss the implications of these findings, taking into consideration the societal effects of a potential correction of the underestimation of abortion rates.
\end{abstract}

Keywords: abortion, perceptions, social norms, misperceptions, pregnancy, availability heuristic

\section{Introduction}

In this study, we identify how often people believe abortions occur and discuss the role of demographic, attitudinal, and behavioral variables in abortion frequency estimates. Additionally, we discuss the societal implications of our findings.

To date, we have found only one other study that assesses how frequently people believe abortions are occurring in the general population (Cowan 2013). While Cowan's work is well done and informative, it measures abortion 
frequency using a cohort perspective. Cowan (2013) asks individuals to estimate the proportion of women that will have an abortion in their lifetime. While this study found that individuals underestimate abortion frequency (believing slightly fewer than a quarter of women would have at least one abortion in their lifetime when the most reliable statistics point to around a third of women, Cowan 2013), we wanted to investigate if the same would be true when asked about abortion rates (i.e. the percentage of pregnancies that will end in abortion) in order to substantiate and triangulate Cowan's finding. Knowing how strongly people feel about abortion and how powerful perceptions of the behavior of others can be on our own attitudes and behavior, we felt a need to continue the nascent exploration of this important area of research.

On the one hand, we saw that abortion was made salient to the public by emotionally charged pro-life advertisements (e.g. those showing aborted fetuses or citing that an abortion occurs every so many seconds); its depiction in popular news, TV shows, and movies; and the religious and political attention afforded to them ${ }^{1}$. Given these factors only, it seemed likely that people would overestimate the percentage of pregnancies that end in abortion, just as people generally overestimate their chances of being killed by a terrorist attack (Glassner 2010) or the percentage of teenage girls that become pregnant (Ipsos MORI 2013), both of which are also very salient in contemporary culture.

On the other hand, whereas terrorism's goal is to cause public havoc and fear and teenage pregnancy is difficult to hide, especially when it goes to term and ends with the birth of an infant, abortion is a largely hidden and secretive process. It is often taboo, even where and when it is legal. Moreover, even in places and under conditions where the majority of people are supportive of an individual's ability to get an abortion, the occurrence of abortions is hardly ever publically declared. While social media is rife with new baby photos and news reports of terrorist attacks or threats, we hardly ever hear of abortions this way.

\section{Abortion Views and Arguments}

Two of the major arguments made by those in favor of abortion rights are that women should have the freedom to control what happens with their own bodies (Shaw 2010) and that outlawing abortion will only lead to an increase in dangerous and hurried illegal abortions (Cates et al. 2007). Other less common lines of reasoning in support of abortion rights are that an unwanted child should not be forced into life; that a gravely sick child should not be forced to live a life of anguish; that a fetus only enters personhood when it is able to live outside of the mother; and that having the option to abort helps close the income gap between men and women (See well-known feminist Katha Pollitt's 2014 book

\footnotetext{
${ }^{1}$ Republican Rick Santorum, a 2012 presidential candidate, incorrectly declared during his campaign "a third of all the young people in America are not in America today because of abortion, because one in three pregnancies end in abortion." See http://www.politifact.com/truth-ometer/statements/2011/mar/31/rick-santorum/rick-santorum-says-one-everythree-pregnancies-end/ 
Pro: Reclaiming Abortion Rights for more on these and other arguments in favor of abortion as a moral right and social good).

Many pro-life advocates believe that abortion is an act of killing, because life starts at conception (e.g. Alcorn 2009). Moreover, they often believe that abortion causes pain and distress to the unborn (e.g. Alcorn 2009). Religious arguments such as prohibition of interfering with the plan of a religious deity and/or supernatural forces are also put forth by pro-life advocates (Wilcox and Gomez 1990). Another pro-life argument is that abortion limits the pool of children available for adoption by those who cannot biologically conceive (Jones 2009). Of course, there is much more complexity to this viewpoint than could possibly be covered here. For an illuminating account of the motivations and thought patterns of pro-life activists, see Maxwell's (2002) anthropological account.

\section{Religious Identification and Abortion Views}

Research suggests that one's views on the legality of abortion are highly correlated with gender and religious affiliation. For example, men have often been found to be less liberal in their views toward abortion than women (Carter, Carter and Dodge 2009). A 2012 Gallup Poll revealed that non-religious Americans were most likely to identify themselves as "pro-choice," with $80 \%$ of respondents choosing that option. In the same poll, Catholics (48\%) were more likely than Protestants/Other Christians (40\%) to self-identify as "pro-choice" (Saad 2013). An earlier study noted that $84 \%$ of Americans practicing Judaism, $81 \%$ of Americans practicing Buddhism, $69 \%$ of Americans practicing Hinduism, and $48 \%$ of Americans practicing Islam felt that abortion should be legal in all or most cases (Pew Forum on Religion \& Public Life 2008).

Even at the official level of individual churches within the large Protestant community in the United States, variability in attitudes toward abortion exists. The official stance of the United Methodist Church, which accounted for 5.1\% of the U.S. adult population in 2007, is that abortion should be legal. However, the Southern Baptist Convention, which claimed $6.7 \%$ of the adult population, is officially against the legality of abortion. Of course, official doctrine and individual views are not necessarily congruent (ProCon.org 2011).

\section{Strength of Abortion Views}

Not only are people's views on abortion inextricably linked to their other major defining characteristics such as gender and religious identification, but people also feel strongly about their abortion stance. Over $20 \%$ of those polled in National Election Studies in 2000 rated the abortion issue as "extremely important" (the highest rating allowed), while $36 \%$ of respondents ranked it as "very important." Perhaps the most significant indicator of the importance of abortion to the citizenry is that $98 \%$ of respondents expressed an opinion in the 2000 poll (Jelen and Wilcox 2003).

These prevalent, powerful, and polarizing views on abortion also affect people's political endorsements and voting behavior. Indeed, people claim to find a political candidate's views on abortion extremely influential in crystallizing 
their view of the candidate. Moreover, Jelen and Wilcox (2003:2) report that abortion is "one of the few issues that consistently appears to influence voting behavior at all levels of government." Abortion is a divisive enough issue that it can even cause people to change political affiliations (Jelen and Wilcox 2003) rather than just creating and/or bolstering their existing political dispositions. Just before the 2012 presidential election, Gallup found that almost $20 \%$ of registered voters said they would vote only for a candidate who was on their side of the abortion debate (Saad 2012). The Pew Research Center also found the abortion issue to be a powerful variable in influencing voting attitudes, with over $60 \%$ of their sample who were against legal abortion stating the issue would be "very important" to their vote. For those favoring the legality of abortion, around $30 \%$ responded with the "very important" option (Pew Research Center for the People and the Press 2012).

\section{Nuances of Abortion Views}

However, we must recognize that the blunt dichotomy of pro-choice versus pro-life overshadows the many people and groups who have nuanced attitudes toward abortions that vary according to factors such as whether or not the mother's health is in danger, whether or not the pregnancy was the result of rape, or according to the trimester of the pregnancy. The aforementioned Gallup study asked respondents if they thought abortion should be legal under any circumstances ( $28 \%$ chose this option), legal only under certain circumstances (52\% chose this option), or never legal (18\% chose this option). Thus, most Americans feel abortion should be legal in some cases and illegal in others (Saad 2013).

More specifically, a 2012 CNN/ORC poll found that almost $90 \%$ of American adults feel that abortion should be legal when the mother's life is endangered, and over $80 \%$ feel that there should be a legal option to abort when the pregnancy was the result of rape or incest (CNN/ORC Poll 2012). In another poll, $19 \%$ of American adults said they believed abortion should be legal in all cases, 36\% said it should be legal in most cases, $25 \%$ said it should be illegal in most cases, and $17 \%$ said it should be illegal in all cases (Washington Post/Kaiser Family Foundation Poll 2012). Again, these numbers can be broken down further and tied to religion, gender, or education level, as well as other variables. For example, in 2007, 59\% of Southern Baptists felt that "abortion should be illegal in all or most cases," whereas only $35 \%$ of United Methodists felt this way (ProCon.org 2011).

Studies on public attitudes toward abortion are ubiquitous. Perhaps the most comprehensive data on this subject comes from the General Social Survey (GSS) conducted by the National Opinion Research Center. Since 1972, the GSS, which seeks to track the opinions, behaviors, and demographic characteristics of Americans, has polled the public on their approval of abortion in different contexts (e.g. if the woman was raped or if the family is poor). GSS data is gathered from a random sample of persons over the age of 18 who are living in the U.S. in non-institutionalized environments. Data is collected using face-toface interviews, computer-assisted personal interviewing, and in rare cases, 
through telephone interviews. In the spring of 2013, Tom W. Smith and Jaesok Son May used decades of GSS data to put together a summary of the nation's attitudes towards the different variants of abortion:

Approval of abortion is highest when the woman's health is seriously endangered (87.0\% across all years, 1972-2012), followed by for pregnancies resulting from rape $(78.3 \%)$, and a serious defect in the fetus $(77.1 \%)$. But majorities have not approved where the family is too poor to afford another child (45.0\%), when a married woman does not want more children $(42.1 \%)$, when the woman is unmarried and does not want to marry the prospective father $(42.0 \%)$, and when the woman wants the abortion for "any reason" (38.5\% for 1977-2012) (Smith and Son May 2013, 2).

\section{Demographic Predictors of Abortion Views}

Smith and Son May (2013) show that demographic characteristics such as age and education are also intertwined with abortion attitudes. Surprisingly, their analysis did not find much difference in attitudes toward abortion between genders. The aforementioned 2012 Gallup poll also did not find much of a gender difference in the percentage of individuals that identify as pro-choice: $50 \%$ of women, and $47 \%$ of men. However, there were other notable demographic predictors of abortion attitudes. Around two-thirds of Democrats declared that they were pro-choice. Similarly, $61 \%$ of those with no college education were pro-choice along with $58 \%$ of those with a household income over $\$ 75,000$ and $41 \%$ of those with a household income less than $\$ 30,000$. Just over a quarter of Republicans stated that they were pro-choice (Saad 2013).

\section{The Relationship between Perceptions of the Behaviors of Others and One's Own Behaviors}

People's perceptions of others' behavior are a strong predictor of their own attitudes and behaviors, especially perceptions about those who are socially close to them (see Pinkerton et al. 2003, Rimal and Real 2003; Perkins 2002; Cialdini and Trost 1998; Beck and Treiman 1996). Understanding the perceptions that the public has about the frequency of abortion incidence will inform our understanding of abortion attitude formation and the related social, political, and legal connections to these attitudes.

While the perception of the frequency of abortions specifically has not drawn scholarly attention, the existence and importance of inaccurate perceptions of peer behavior has long been documented (see Perkins and Berkowitz 1986; Ross, Greene, and House 1977 for some early authoritative work in the area). Additionally, the sub-field of population innumeracy has documented that people generally overestimate the number of racial minorities, gay people, and welfare recipients, among other things, as well as underestimate the proportion of majorities in the population (Lawrence and Sides 2011).

Research has shown misperceptions of sexual and health-related behavior of others. For example, Scholly et al. (2005) found that undergraduates at four institutions "overestimated their peers' levels of sexual activity, number of 
partners, incidence of sexually transmitted infections, and rates of unintended pregnancies, but underestimated rates of condom use." Lambert, Kahn, and Apple (2010) found that both men and women college students believed, in general, that other students were more comfortable engaging in sex acts with each other without any expectation of commitment than they were themselves. Pinkerton et al. (2003) found that college-age women overestimated the degree to which their male counterparts masturbated, while an earlier study found cross-gender overestimation of masturbation frequency to occur in both directions, with the degree of overestimation being the largest when men were asked to assess the frequency of female masturbation (Clark 1999). Lastly, a 2013 study commissioned by the Royal Statistical Society and King's College London shed light on various ways the British people misperceived population demographics and the incidence of social issues. Their top-rated misperception was teenage pregnancy: "on average, we think teenage pregnancy is 25 times higher than official estimates: we think that $15 \%$ of girls under 16 get pregnant each year, when official figures suggest it is around 0.6\% (Ipsos MORI 2013)."

The documentation of misperceptions of the frequency of engagement in particular activities is not confined to especially private behaviors, like frequency of intercourse or masturbation. There are many studies that exemplify and characterize human misperceptions of the true attitudes and behaviors of others (or even of themselves), even when these attitudes and behaviors are seemingly represented in public. Berkowitz (2004) reports that people systematically misperceive the frequency that others binge drink, use drugs, gamble, engage in bullying behavior, hold homophobic attitudes and behaviors, and engage in gang behavior, among other things.

At times, demographic differences in the perceivers have been linked to the likelihood and extremity of the occurrences of misperceptions. Similar to the aforementioned Clark (1999) study on masturbation, many studies on perceptions of the alcoholic drinking behavior of generic others have found that males and females differ in their assessments. Borsari and Carey (2003) performed a metaanalysis on 23 studies that compared self-reported drinking rates to the perceived drinking rates of others. The researchers discovered that, on average women tended to overestimate drinking norms to a greater extent than did men.

\section{Why Do We Misperceive the Social World?}

Popular social psychological concepts like the bystander effect, pluralistic ignorance, the fundamental attribution error, false consensus, false uniqueness and others explain how humans, given a certain social situation (e.g. being in a crowd of people seemingly disinterested in another's possible need for help), regularly make judgments about the social situation (e.g. this is not an emergency) and the motives, attitudes, and behaviors of others (e.g. everyone in this crowd feels this is not an emergency) that consistently and predictably skew our perceptions away from representing the objective reality of the situation. ${ }^{2}$

\footnotetext{
${ }^{2}$ See Behavioral Economist Dan Ariely's book, fittingly entitled Predictably Irrational: The Hidden Forces That Shape Our Decisions which depicts many of Michigan Family Review, 19(1), 26-50, 2015. DOI: 10.3998/mfr.4919087.0019.102 (C) Michigan Council on Family Relations
} 
Berkowitz, the champion of The Social Norms Approach, which seeks to correct misperceptions with the ultimate goal of behavioral changes, describes some of the mechanisms that lead to social misperceptions:

For example, the majority who engage in healthy behavior may incorrectly believe they are in the minority (pluralistic ignorance). In contrast, the minority of people with unhealthy attitudes and/or behaviors may incorrectly think that they are in the majority (false consensus). Finally, an individual may enjoy thinking that her or his behavior is more unique than it really is (false uniqueness) (Berkowitz 2004, 7).

Although much of the literature on misperceptions of the social world frames these heuristics and cognitive biases in a negative light, misperceiving social reality can be a useful and economical practice. For example, believing that you are above average in some way -even when an objective analysis would indicate you are not (commonly known as the Lake Wobegon Effect ${ }^{3}$ ) -may make you less nervous in social situations leading to more dates and job opportunities. Another example is the availability heuristic, which states that people use information that is readily available to them (e.g. salient memories) in order to make predictions/judgments about things (Oskamp and Shultz 2005), which is especially useful in situations in which swift actions are needed and/or when additional data is hard to find. However, when a person's current knowledge of a certain phenomenon is not representative of the larger situation that the person is making a judgment about, this heuristic can lead to misperceptions (e.g. "no one I know has ever told me they had an abortion, therefore abortions never occur," or "the media and politicians are always talking about abortion, therefore abortions must occur very often"4).

\section{Objectives of the Study}

Building on prior research, in this paper we argue that understanding the perceptions the public has about the frequency of abortion incidence is crucial to gauge abortion attitude formation and related social, political, and legal connections. We measured people's perceptions of the likelihood a pregnant

the cognitive short-cuts humans take and highlights the situations where these short-cuts systematically lead to misperceptions about the social world.

${ }^{3}$ Named after radio personality Garrison Keillor's fictional town "where all the women are strong, all the men are good-looking, and all the children are above average."

${ }^{4}$ The widespread notion that the world is more dangerous than ever and that you can't be too careful "these days" is often attributed to the salience of violence and its prominence in "if it bleeds, it leads" newsrooms. Most scholarship shows, however, that the world may be enjoying its least violent time in human history. See Harvard psychologist Steven Pinker's 2011 book The Better Angels of Our Nature: Why Violence Has Declined for a review of this literature and a voluminous scholarly depiction of the lessening of murders and rapes per capita over time.

Michigan Family Review, 19(1), 26-50, 2015. DOI: 10.3998/mfr.4919087.0019.102 (C) Michigan Council on Family Relations 
women will have an abortion in the U.S. and in their state (i.e., Michigan). We identified how these perceptions differ based on a range of demographic, attitudinal, and behavioral characteristics. Ultimately, we are interested in finding out how accurately people estimate abortion rates and if these estimates meaningfully vary according to the demographic, attitudinal, and/or behavioral differences among the estimators.

\section{Data and Methods}

Primary data for our study comes from an online survey developed on SurveyMonkey and distributed via email listservs to students, faculty, and staff of two U.S. universities to which the authors had access. Upon gaining IRB approval from the primary research institution, we collected data during the period January - May 2013. We initially distributed the survey link through available email listservs, following which a snowball sample was generated through self-selection and redistribution of the link by respondents' to their own networks. In the fiveto-ten minute survey, we asked respondents questions on how they feel about abortion. We explained in the consent form that since "abortion is a hot-button issue, it is important that we understand peoples' opinions about abortions as accurately as possible." Hence, we asked respondents to indicate their estimates of the prevalence of abortions in the U.S. and in their state. At the end of the data collection period, we received 157 total responses. After cleaning the data and removing missing values, we retained 155 usable observations.

The convenience sample generated through email listservs does raise questions about generalizability because we have used a non-probability sample that is not representative of the general population of the U.S. or that of Michigan. The survey respondents were limited to those with literacy and access to web resources. Respondents were not representative of the population of the country or a particular geographic location (Couper 2011; Bhutta 2012). Additionally, online convenience samples from prior research have reported biases where respondents tend to be disproportionately young, female, and well educated, which we also encountered in our own research (Bhutta 2012; Hampton et al. 2011). Due to these data limitations, our results cannot be generalized beyond the population defined by the sample that we have used (largely female, young, and comparatively highly educated). However, we believe that our research findings provide an exploration of an important, understudied aspect of an issue of critical societal and family health value. While considering this as an initial exploratory study, we hope future studies will look for replications of the findings using multiple, larger, and representative samples, as well as multiple methods.

Table 1 summarizes the relevant questionnaire items, proportions, and frequencies for the main independent and dependent variables used in our study. The survey measured several independent variables including demographic characteristics (gender, age, race, education, strength of religious affiliation, political orientation), attitudinal and behavioral measures, as well as four main dependent variables. For demographic variables, including strength of religious affiliation and political orientation, we used the same question stems and categorizations of the GSS, as a way of gauging external validity. 
Our main dependent variables are respondent estimations of the (a) percentage of all unwanted pregnancies in the U.S. that end in abortion, (b) percentage of all unwanted pregnancies in the respondent's state that end in abortion, (c) percentage of all pregnancies (both wanted and unwanted) in the U.S. that end in abortion, and (d) percentage of all pregnancies (both wanted and unwanted) in the respondent's state that end in abortion. The specific questionnaire wording for the dependent variables is stated below:

The next few questions deal with percentages. Percentages are ways of measuring how many times out of a 100 something is likely to happen. Thus, if a coin lands on heads half the time and on tails half the time, it has a 50 percent chance to land on heads and a 50 percent chance to land on tails.

Q1: To the best of your knowledge, what percentage of all unwanted pregnancies in the U.S. end in abortion?

Q2: To the best of your knowledge, what percentage of all unwanted pregnancies in your state end in abortion?

Q3: To the best of your knowledge, what percent of all pregnancies (both wanted and unwanted) in the U.S. end in abortion?

Q4: To the best of your knowledge, what percent of all pregnancies (both wanted and unwanted) in your state end in abortion?

Responses to these four dependent variables were collected on scales ranging from $0 \%$ to $100 \%$, with $10 \%$ increments. We recoded the dependent variable to "underestimate," "accurate estimate" and "overestimate," within the $10 \%$ incremental scale. This recoding allowed for Chi-square analysis of estimation accuracy. Recoding was done by comparing the respondents' abortion estimates to a baseline of existing estimates of abortions from governmental records (i.e. CDC) and NGO records (i.e. Guttmacher Institute). These are the selected baseline data points: (a) $43 \%$ of all unwanted pregnancies in the U.S. end in abortion (Guttmacher 2013), (b) 34\% of all unwanted pregnancies in Michigan end in abortion (Guttmacher 2012), (c) 22.8\% of all pregnancies (both wanted and unwanted) in the U.S. end in abortion (CDC 2013), and (d) 20.2\% of all pregnancies in Michigan (both wanted and unwanted) end in abortion (CDC 2013). In addition to the four main dependent variables, the coding scheme for independent variables is shown in Table 1 below, along with the corresponding percentages and $\mathrm{N}$ values for the different answer categories.

In the results presented below, we restricted the "state level" analysis to Michigan, where approximately $80 \%$ of the respondents in the sample indicated living at age 16. Thirty-two respondents were living outside of Michigan and their responses were not included in the state-level analysis. All responses (for those living in and outside of Michigan) were included in the country-level analysis. We used Chi square analysis to identify any possible associations between 
respondents' demographic characteristics, attitudes toward abortion, behavioral characteristics, and their abortion estimates. We also report some exploratory univariate findings on respondents' attitudes towards circumstances under which abortion should be allowed.

\section{Descriptive Statistics}

\section{Results}

Descriptive statistics for the variables used in the study are reported in Table 1. The frequencies and percentages displayed reveal that the sample consisted mainly of young adults aged 18 to 35 with considerably high levels of education compared to the general population of the U.S. (Over $60 \%$ of the respondents had at least an associate's degree; however, according to the 2010 U.S. Census report, only $36 \%$ of the general population over 25 years of age have at least an associates-level educational attainment). Approximately $71 \%$ of the respondents were female, which is not surprising as prior studies have reported instances where women are more expressive of their attitudes towards abortion and considered abortion as a relevant and/or "hot topic" as opposed to men (e.g., Salmon 1990). There was some diversity among religious affiliations and political orientations in the sample. Twenty-five percent of the respondents indicated that the strength of their religious affiliation is very strong as opposed to $34 \%$ who indicated that their affiliation is "not strong at all." Fifty-eight percent of the respondents were politically liberal. Eighty-seven percent of the respondents were white. Eighty-four percent of the respondents reported having received some form of sex education in their grade 5 through 12 education. About $50 \%$ of the individuals received safe sex education, while approximately $25 \%$ received abstinence-only education. Ninety-seven percent of the participants indicated that they are in favor of sex education in public schools, and the majority preferred safe sex (79.5\%) as opposed to abstinence-only sex education (10.3\%). In terms of sexual health behaviors, $87 \%$ reported having had at least one sex partner over the last 5 years. More than $50 \%$ of the individuals in the sample reported having used some form of birth control the last time they engaged in vaginal intercourse. Furthermore, as seen in Table 1, exploratory findings on attitudes toward abortion indicate that nearly half of the survey sample believed that abortion is a "very important" issue to them. Twenty percent of the respondents indicated that they think about topics related to abortion "often," while 49.3\% indicated that they think about topics related to abortion "sometimes."

Table 1: Descriptive statistics for survey sample $(\mathrm{N}=155)$

\begin{tabular}{l|lll}
\hline Variable & Coding & Percent & $\mathbf{N}$ \\
\hline Age & $18-25$ & 35.0 & 54 \\
& $26-35$ & 44.8 & 69 \\
Gender & $>36$ & 20.1 & 31 \\
& Female & 71.6 & 111 \\
Education & Male & 28.8 & 44 \\
& High school/GED & 36.9 & 58 \\
\hline
\end{tabular}




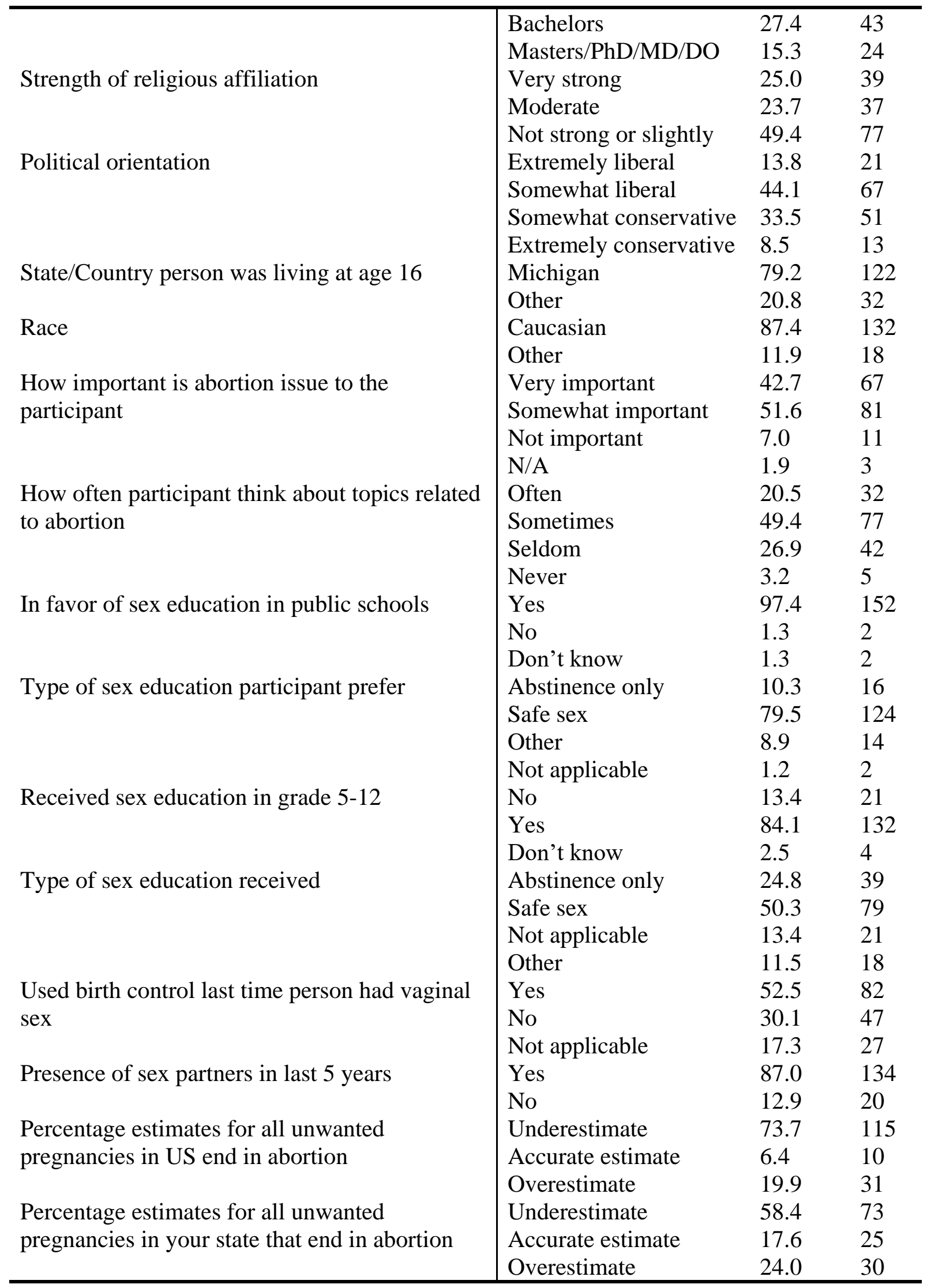




\begin{tabular}{l|lll}
\hline Percentage estimates for all pregnancies (both & Underestimate & 49.0 & 76 \\
wanted and unwanted) in US end in abortion & Accurate estimate & 21.9 & 34 \\
& Overestimate & 29.0 & 45 \\
Percentage estimates for all pregnancies (both & Underestimate & 30.9 & 48 \\
wanted and unwanted) in your state end in & Accurate estimate & 44.5 & 69 \\
abortion & Overestimate & 24.5 & 38 \\
\hline
\end{tabular}

Frequency distributions of the 4 dependent variables, presented in Figures 1- 4 below, allow for further visual comparisons of participants' estimates of abortion rates to the official estimates. These figures reiterate that most respondents in our sample under-estimate the abortion rates, both for the U.S. and for Michigan.

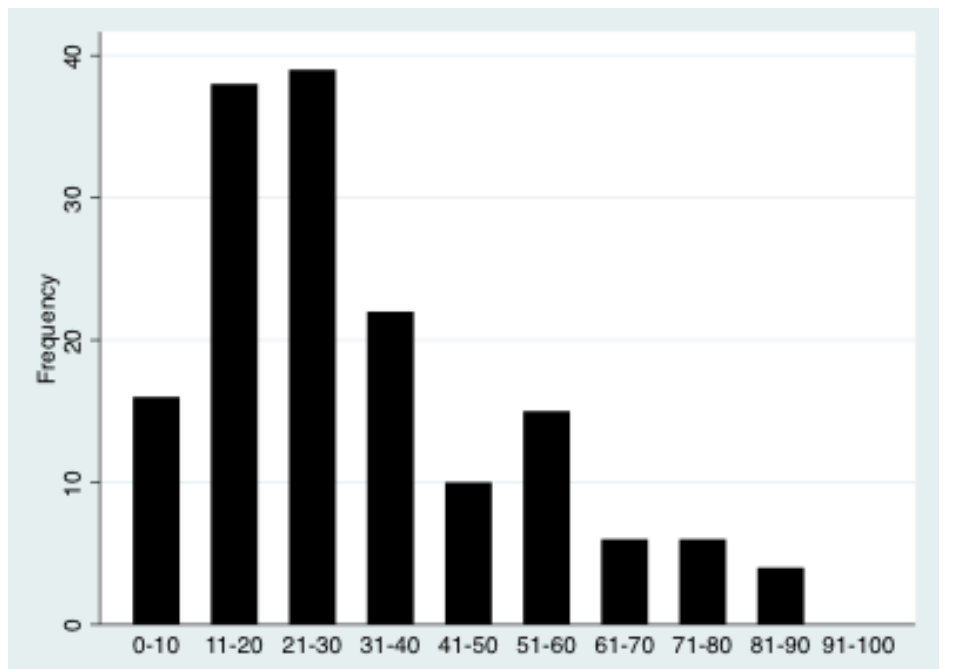

FIGURE 1: Percentage estimates for all unwanted pregnancies in U.S. that end in abortion 


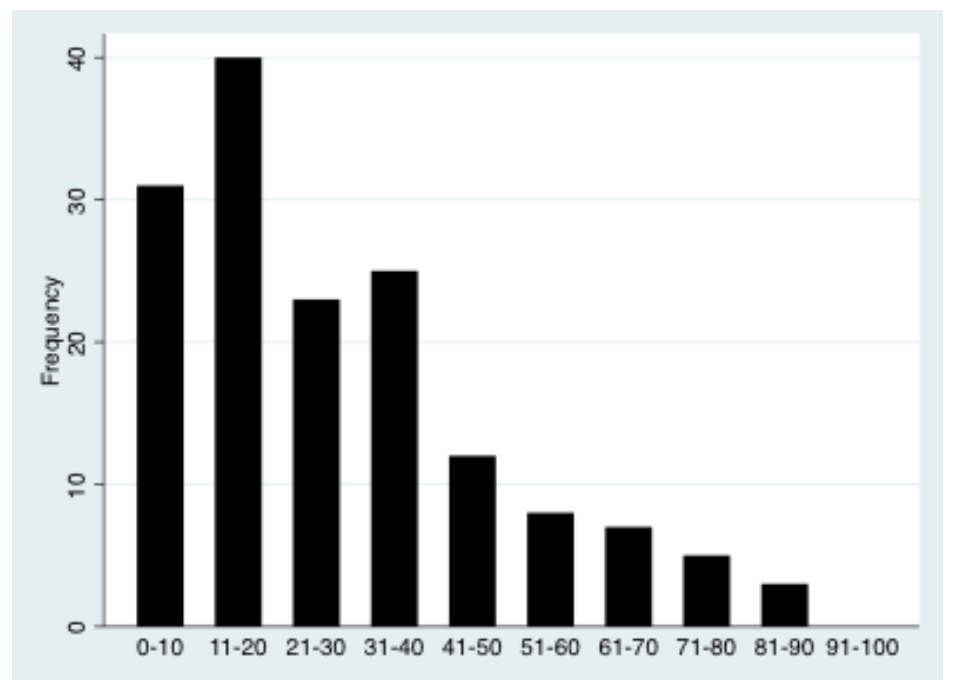

FIGURE 2: Percentage estimates for all unwanted pregnancies in Michigan that end in abortion

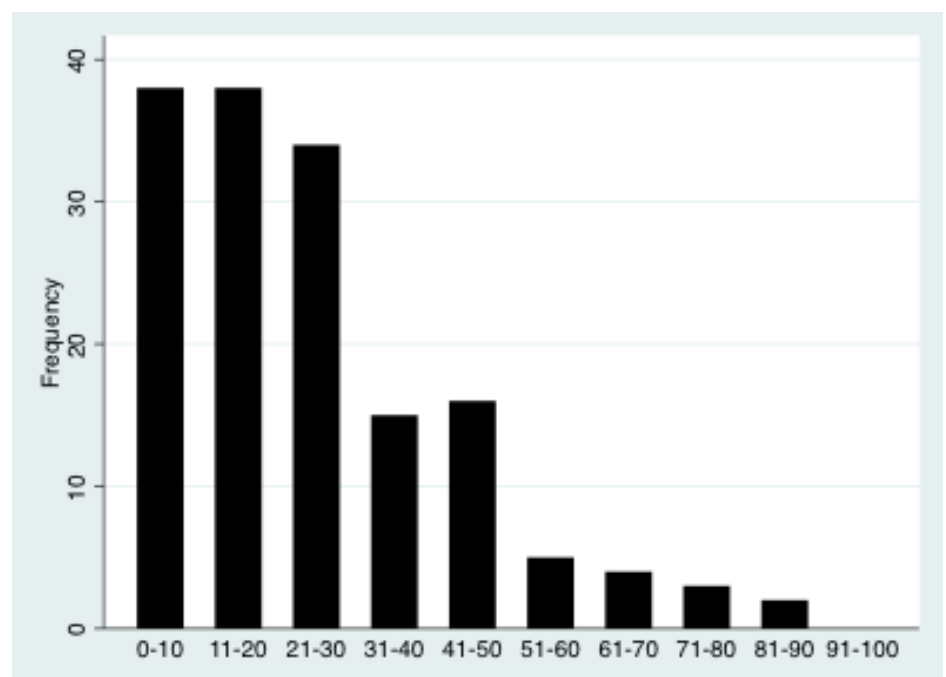

FIGURE 3: Percentage estimates for all pregnancies (both wanted and unwanted) in U.S. that end in abortion 


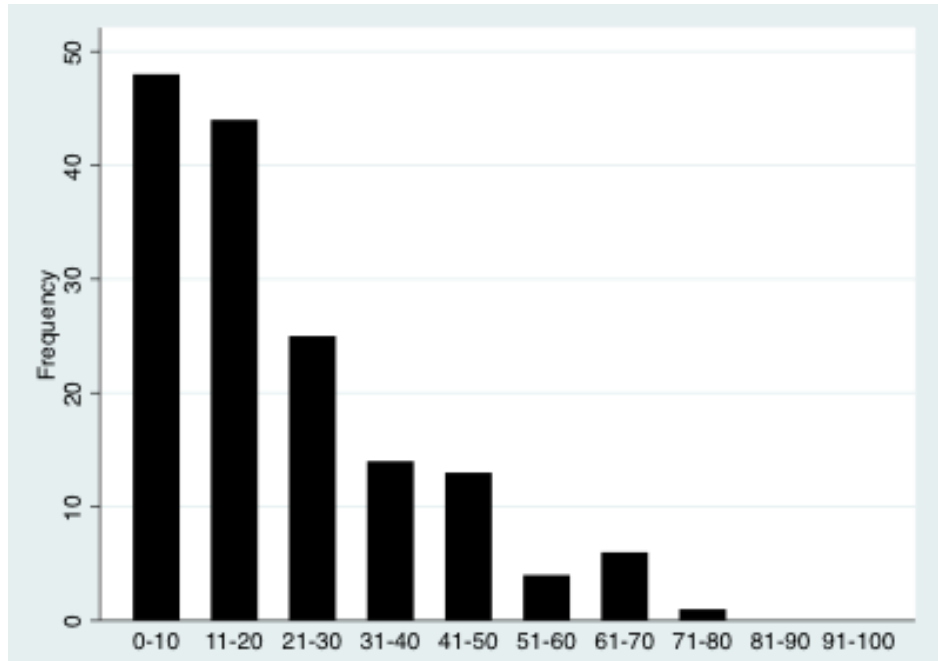

FIGURE 4: Percentage estimates for all pregnancies (both wanted and unwanted) in Michigan that end in abortion

Table 2 summarizes participants' perceptions of scenarios under which abortion should be allowed. These perceptions were variable with an overwhelming percentage agreeing that abortion should be allowed if a woman's own health is endangered due to pregnancy or if a woman becomes pregnant as a result of rape ( $80.8 \%$ and $74.4 \%$ respectively). Consistent with previous literature, considerable support was also seen for abortion when there is a strong chance of a serious defect in the baby (56.7\%). Significantly less support is expressed for abortion when the pregnancy has passed the first trimester $(31.4 \%)$, and even less support is exhibited after the second trimester (15.9\%). Only $39.1 \%$ of the survey respondents agreed that abortion should be allowed if a woman wants it for any reason.

TABLE 2: Scenarios in which abortion should be allowed, affirmative percent, $(\mathrm{N}=155)$

\begin{tabular}{l|l}
\hline Family has low income and cannot afford more children & $\begin{array}{l}\text { Percent in the } \\
\text { affirmative }\end{array}$ \\
Woman becomes pregnant as a result of rape & 51.2 (yes) \\
74.4 (yes) \\
Pregnancy has passed first trimester & 31.4 (yes) \\
Pregnancy has passed second trimester & 15.9 (yes) \\
Father is aware of pregnancy and want the baby to be born & 28.8 (yes) \\
Father is unaware of pregnancy & 37.8 (yes) \\
Woman's own health is endangered due to pregnancy & 80.9 (yes) \\
Woman is not married and does not want to marry the father & 39.7 (yes) \\
Father aware of pregnancy and wants to terminate pregnancy & 27.4 (yes) \\
There is a strong chance of a serious defect in the baby & 56.7 (yes) \\
Woman wants it for any reason & 39.2 (yes) \\
Woman is married and does not want any more children & 43.9 (yes) \\
\hline
\end{tabular}


As seen in Table 1, the respondents' abortion estimates vary significantly and were often inaccurate in comparison to the most reliable data available to us at the current time. Only $6.4 \%$ of the respondents were able to accurately estimate the percentage of all unwanted pregnancies in the U.S. that end in abortion. This is significantly lower than the percentage that accurately estimated the percentage of all pregnancies (both wanted and unwanted) in U.S. that end in abortion (21.9\%). When considering state-level (Michigan) estimates, $17.6 \%$ of respondents were able to accurately estimate the percentage of all unwanted pregnancies in their state that end in abortion. Additionally, a considerably higher percentage of respondents accurately estimated the percent of all pregnancies (both wanted and unwanted) in Michigan that end in abortion (44.5\%).

\section{Associations between Abortions Estimates and Demographic Characteristics}

We used Chi square analysis to determine if there were any associations between accuracy of estimations of abortion rates and demographic characteristics as well as attitudes toward abortion. The percentage of participants that accurately determined the abortion rate for all pregnancies in the U.S. (both wanted and unwanted) differed by gender, $X^{2}(2, \mathrm{~N}=153)=5.67, p<.05$. Women were significantly more likely to overestimate the abortion rate for all pregnancies in U.S. (33.9\% of women as opposed to $18.1 \%$ of men), while men were significantly more likely to underestimate the abortion rate $(63.6 \%$ men as opposed to $43.1 \%$ women) (Table 3).

TABLE 3: Association between gender and abortion estimates for all pregnancies in $U S$ that end in abortion (percentage and count)

\begin{tabular}{|l|l|l|}
\hline \multirow{2}{*}{ Abortion estimate } & \multicolumn{2}{|c|}{ Gender } \\
\cline { 2 - 3 } & Female & Male \\
\hline Under estimate & $43.12 \%$ & $63.64 \%$ \\
& $(47)$ & $(28)$ \\
\hline Accurate estimate & $22.94 \%$ & $18.18 \%$ \\
& $(25)$ & $(8)$ \\
\hline Over estimate & $33.94 \%$ & $18.18 \%$ \\
& $(37)$ & $(8)$ \\
\hline Total & $100 \%(109)$ & $100 \%(44)$ \\
& & \\
\hline
\end{tabular}

$\chi^{2}=5.67 ; \mathrm{df}=2 ; \mathrm{p}<.05$

We found that the percentage of participants that accurately determined the abortion rate for all pregnancies in the U.S. differed by age as well, such that $X^{2}(4, \mathrm{~N}=152)=9.79, p<.05$. In the 26-to-35 age category, most individuals underestimated the abortion rate for the U.S. (61.8\%), whereas the highest percentage of accurate estimates was seen amongst people over 35 years of age (26.7\%) (Table 4). 
TABLE 4: Association between age and abortion estimates for all pregnancies in $U S$ that end in abortion (percentage and count)

\begin{tabular}{|l|l|l|l|}
\hline \multirow{2}{*}{$\begin{array}{l}\text { Abortion } \\
\text { estimate }\end{array}$} & \multicolumn{3}{|c|}{ Age } \\
\cline { 2 - 4 } Under estimate & $18-25$ & $26-35$ & $>35$ \\
\hline Accurate estimate & $40.74 \%$ & $61.76 \%$ & $36.67 \%$ \\
& $(22)$ & $(42)$ & $(11)$ \\
\hline Over estimate & $(11)$ & $20.57 \%$ & $\begin{array}{l}26.67 \% \\
(8)\end{array}$ \\
& $(21)$ & $17.65 \%$ & $36.67 \%$ \\
Total & $100 \%(54)$ & $(12)$ & $100 \%(30)$ \\
& & $100 \%(68)$ & \\
\hline
\end{tabular}

$\chi^{2}=9.79 ; \mathrm{df}=4 ; \mathrm{p}<.05$

The percentage of participants that accurately determined the abortion rate for unwanted pregnancies in the U.S., both wanted and unwanted pregnancies in Michigan, and unwanted pregnancies in Michigan did not differ by education, race, gender, age, religious affiliation, or political orientation. Furthermore, we did not find any significant associations between the abortion estimates and the attitudinal and behavioral measures tested in this study. Overall results indicate that some significant associations do exist between people's estimates of abortion rates and their demographic characteristics that need to be further investigated through causal analysis.

\section{Discussion}

Respondents were more likely to underestimate than accurately estimate or overestimate the percentage of pregnancies that ended in abortion in three of the four estimates about which we asked: all pregnancies in the U.S., unwanted pregnancies in the U.S., and unwanted pregnancies in Michigan (the most popular estimate for all pregnancies in Michigan being accurate). The idea that humans do not possess perfect knowledge about the behaviors of others has been well established (e.g. Berkowitz 2004; Gilens 1996; Prentice and Miller 1993). We must pay attention to these, often inaccurate, subjective perceptions because "people act on their perceptions of their world in addition to acting within a real world" (Perkins and Wechsler 1996:962).

Our misperceptions about the social world are usually attributed to any number of judgmental heuristics. Many of these were introduced to the scientific world by Daniel Kahneman and Amos Tversky in a 1974 article in Science (Tversky and Kahneman 1974). ${ }^{5}$ The availability heuristic could be a reason why we found a general underestimation of the degree to which pregnancies end in abortion. The availability heuristics states that there is a relationship between the

\footnotetext{
${ }^{5}$ Since a seemingly endless number of heuristics have sprouted up from rigorous and not-so rigorous research and interpretation, many of these have been used in an ad-hoc fashion to explain researchers' findings of perceptual errors and mis-estimations (and can even be used in ways that seem to offset each other, e.g. what is rare makes a big impact, but what is usual also makes a big impact).
} 
ease with which examples of a certain phenomenon come to mind and the likelihood we attribute to that event occurring in the larger social world and its importance in that larger social world (Tversky and Kahneman 1973). Researchers have found evidence of this heuristic influencing the way we judge whether or not we think a product will succeed (Folkes 1988), our perceptions of the prevalence of depression (An 2008), our perception of the quality of lives others lead (Chou and Edge 2011), among many other applications.

Perhaps due to the strong stigma surrounding abortion, women are unlikely to disclose to others that they have had an abortion. Cowan (2013) found that individuals knew more people who had had miscarriages than abortions, even though abortions actually occur more frequently. She argues that abortion stigma is much greater than miscarriage stigma and that this leads to less people divulging that they have had an abortion. Clearly, more studies are needed to not only replicate what we have found here but also to investigate the mechanisms contributing to the overall underestimation.

Still, the mere presence of this general underestimation has several societal implications. Most basically, scholars have established that there is a strong correlation between how often people think their peers act in a certain manner and the likelihood that they will act in a similar way, (i.e. we do as we think others do). Moreover, social norms campaigns have succeeded in demonstrating that a change in the perception of the behavior of others leads to a behavioral change in the same direction (Berkowitz 2004). Longitudinal studies in this area provide good evidence for establishing the causal influence of perceived peer behavior (see Perkins 2003 for some of these).

So, the underestimation may have the ultimate effect of producing less abortions in the population than would occur if people accurately perceived the abortion likelihood. Of course, unlike many existing studies on the effects of misestimations on behavior (e.g. those on alcohol consumption), this topic is unique because only a portion of the population (and our sample) have even the slightest potential of receiving an abortion. Only females of reproductive age receive abortions and those two variables, age and sex, are extremely difficult to change. Perhaps if we are concerned with the behavioral effects of the perception of the behavior of others in this realm, we should limit our analysis to the perceptions of those who have the basic potential to receive an abortion. Both gender and age had some effect in some of our study conditions, but overall, gender and age effects did not negate the tendency towards underestimation.

Likewise, we did not find a relationship between questions regarding sexual frequency and abortion estimates. Despite the relevance of limiting the sample of perceptions we measure if we wish to determine perceptions effects on behaviors, we must remember that abortions occur in social contexts. The opinion of partners, parents, social workers, doctors, religious leaders -all of whom have their own perceptions about the likelihood of abortions ending in pregnancies -stand to influence abortion decisions. Future studies should consider these nuances in study designs and interpretations.

In addition to its role in lessening the number of abortions in the population, the underestimation may play a causal role in determining the 
frequency with which people have sexual intercourse, have sexual intercourse with the goal of procreating, and have sexual intercourse without birth control. Individuals who wish to have sex without creating a fetus are probably more likely to engage in sexual intercourse when they think the likelihood of pregnancy is low. All other things being equal, believing abortions occur less than they actually do translates into believing pregnancies happen less frequently than they actually do. Still, if people who do not wish to have a baby believe that very few others are having abortions, they might also be compelled to engage in less pregnancy-inducing behavior.

It might be easier to articulate these points if we frame them as what might happen if the underestimation was corrected to an accurate estimation. Here are two logically and generally empirically-supported, albeit opposite, outcomes of a correction of the mis-estimation of abortion rates: 1) People not wishing to conceive may engage in less vaginal intercourse, especially sans birth control, out of an increased fear of becoming pregnant (i.e. more abortions are more evidence of pregnancies); 2) conversely, these same people may engage in more vaginal intercourse, even with birth control, as they feel more justified, able, or are more willing to have a potential pregnancy aborted.

However, sometimes when people come to find that something is occurring much more frequently than they previously thought, this compels them not to join in committing the same act, or standing idly by, or believing it to be more moral. Instead, this awakening serves to compel the person to act out against the issue, a phenomenon known as the boomerang effect (e.g. see Shultz et al. 2007). So, finding out that no one in your city recycles might just be the tipping point that causes you to start recycling, or finding out that most people do not intervene when someone is getting bullied might spur you to be extra ready to step up to bullies.

In addition to the general finding of underestimation, we found a gender difference in one of the four conditions -all pregnancies in the U.S. Although our sample underestimated as a whole, women were more likely than men to overestimate the abortion rate. On the other end, men were more likely than women to underestimate the abortion rate in the same condition. This may be because only women get abortions and the issue is more salient among women's social circles and women's everyday lives. Furthermore, the evidence that women's estimates were more likely to center around the true statistic is congruent with the pervasive finding in other studies that social distance is directly correlated with the size of mis-estimation (e.g. Beasley 2010, Berkowitz 2004, Borsari and Carey 2003); the closer one is to the people he/she is asked about, the more accurate his or her answers will be. In this case, women may be more apt to accurately gauge abortion frequency than men. Of course, it is important to note that we did not find a significant gender effect in our other conditions.

In two of our conditions, age was also significantly related to abortion estimates. In the condition regarding all abortions in the U.S., younger individuals were more likely than other age groups to underestimate, while older individuals were more likely than other age groups to accurately estimate the true statistic of 
22.8\%. When we asked about all pregnancies in Michigan, the youngest group was more accurate compared to the older groups -the true statistic is $20.2 \%$. This may have been a result of our methods for the "Michigan" conditions, where we asked people about abortion "in their state" and included responses of those that said they were living in Michigan at the age of 16. It stands to reason that younger people who were in Michigan at the age of 16 would still be in Michigan and would have a less obscured view of abortion frequency in Michigan than older individuals who may live in a different state.

Gender and age were not significantly associated with abortion estimates in the other conditions. Moreover, none of the other demographic, behavioral, or attitudinal variables were significantly associated with any of the conditions. More research is needed to determine if factors such as religious and political affiliation, sexual activity, and educational level truly do not influence abortion rate estimates.

\section{Limitations}

As we used a convenience sample in this study, extreme caution should be used in generalizing our findings. The percentage of women and people with advanced degrees were higher in our sample than they are in Michigan or the U.S. as a whole. More than that, in order for an individual to respond to the survey, he or she had to see our invitation (those socially close to us were the most likely), and have sufficient time, know-how, and motivation to fill it out. Those that selfselected into our sample most likely differed in meaningful ways (including their perceptions towards abortion) from some general populations of interest (e.g. U.S. adult citizens, Michigan college students, likely voters). As mentioned before, this sampling bias does raise significant issues of generalizability. However, we argue that our study is useful, albeit preliminary, in that it draws attention to a phenomenon that has not been addressed sufficiently in existing literature.

Our subjects may have also been affected by social desirability bias, even though we assured them that their responses would be anonymous. After all, we asked about highly sensitive topics (e.g. sexual behavior, religion, politics, and abortion). Furthermore, respondents' understanding and interpretation of the questions may have differed from one another and from our intention. For example, people certainly think of different things when asked about abortion (e.g. whether the abortion is induced or spontaneous, legal or illegal, done in the first-trimester-only or any trimester, regarding a viable fetus, whether the mother's health is in danger, or if the likely quality of life for the fetus if significant in any way). Still, we did ask a basic question about what respondents think of when asked about abortion to gain some idea of the mental frames with which they were operating.

When comparing our subjects' estimations of abortion rates to official statistics, we must be aware that the official statistics do not necessarily represent an objective and accurate representation of the true incidence of abortion. For example, the CDC statistics we used are tracking only those abortions that occur as interventions "performed by a licensed clinician (e.g., a physician, nursemidwife, nurse practitioner, or physician assistant) that [are] intended to terminate 
a suspected or known ongoing intrauterine pregnancy and produce a nonviable fetus at any gestational age (Pazol et al. 2011)." Furthermore, the CDC is at the mercy of the compliance of reporting agencies which may voluntarily choose not to report cases or limit the types of cases they do report. Meanwhile, the Guttmacher Institute's statistics come from surveys of legal abortion providers. While the institute uses a variety of methodologies (e.g. extensive follow-ups including interviews) to counteract the usual pitfalls of survey research (e.g. response bias), the data produced is still describing only the number of legal abortions. The incidence of illegal and/or "unsafe" abortions are difficult for researchers to determine (Ahman and Shah 2010).

We do know, however, that some number of abortions occur outside the scope of the CDC's and Guttmacher Institute's standard tabulating procedures because of lack of access to abortions, the stigma surrounding them (Cockrill and Nack 2013; Shellenberg et al. 2011), or other reasons (Singh, Remez, and Tartaglione 2011). In April 2014, the Huffington Post ran a story that claimed that pregnant Americans "once again find themselves crossing the border to Mexico and haunting back-alleys in search of medical care" and/or are "attempting risky self-abortion procedures (Bassett 2014, http://www.huffingtonpost.com/2014/04/03/back-alley-abortions_n_5065301.html)."

Similarly, according to Ibis Reproductive Health researcher Dan Grossman, with the implementation of stiffer regulations in Texas, there have been reports of women taking herbs or other substances or intentionally getting punched in the stomach or beaten up, i.e. the same kinds of things they did before abortion was legal. "There also seems to be a lot of illegal obtainment and use of the prescription abortion pill misoprostol or of other substances masquerading as the drug. However, many pro-life advocates see work like that of Grossman as nothing more than inflationary political scare tactics (Bassett 2014, http://www.huffingtonpost.com/2014/04/03/back-alley-abortions_n_5065301.html).” Regardless, we do not know for sure how many abortions take place outside of the legalized medical domain.

Still, since we found an underestimation of abortion rates, the discovery or tabulation of additional abortions will only increase the degree of the underestimations. So while this limitation certainly affects the precision of our calculations, it should not invalidate our general argument and findings.

We also encountered a data limitation due to collecting respondents' abortion estimates on a $0-100 \%$ scale with $10 \%$ increments. We are unable to pinpoint whether the intended estimates are closer to the lower boundary or the upper boundary of the incremental category. This may have caused some errors of our recoding of the abortion estimates. As a result, we must reiterate that our operationalization of "accurate estimate" is an approximation, along with the "underestimate" and "overestimate" categories. Future research may consider using open ended questions to gauge the abortion estimates, while keeping in mind that they too may cause data collection issues such as higher percentages of missing values. 


\section{Conclusion}

Although such a powerful and divisive issue, little research has been done to determine people's perceptions of the frequency of abortion in the population. With other similar issues, people have been found to, on average, mis-estimate the degree to which others do or believe something. These misperceptions are important because they have been shown to be related to personal behaviors; we are influenced by the perceptions of the thoughts and behaviors of others. Our sample, as a whole, underestimated how many pregnancies end in abortion. Following the logic and evidence of earlier studies on similar issues and principles, this underestimation likely causes different abortion and sexual behavior than would occur if people accurately estimated the prevalence of abortions.

\section{Acknowledgments}

The authors are thankful to Meaghan Beasley and Naomi Glogower for their valuable insights, as well as three anonymous reviewers for helpful suggestions on a previous version of this article.

\section{References}

Ahman, E., \& Shah, I. H. (2010). Generating national unsafe abortion estimates: Challenges and choices. Pp. 13-22 in S. Singh, L. Remez, and A. Tartaglione (Eds.,), Methodologies for estimating abortion incidence and abortion-related morbidity: A review. Guttmacher Institute. Retrieved August 1, 2014. (http://www.guttmacher.org/pubs/compilations/IUSSP/abortionmethodology.html)

Alcorn, R. (2009). Pro-life answers to pro-choice arguments. New York, NY: Doubleday Religious Publishing Group.

Ariely, D. (2010). Predictably irrational, revised and expanded edition: The hidden forces that shape our decisions. New York, NY: Harper Perennial.

American Fact Finder. 2012. Educational attainment, 2008-2012: American Community Survey 5-Year estimates. United States Census Bureau. Retrieved May 21, 2014. (http://factfinder2.census.gov/faces/tableservices/jsf/pages/productview.xh tml?pid=ACS_12_5YR_S1501).

An, S. (2008). Antidepressant direct-to-consumer advertising and social perception of the prevalence of depression: Application of the availability heuristic. Health Communication 23(6): 499-505. doi: 10.1080/10410230802342127.

Bassett, L. (2014). The return of the back-alley abortion. Huffington Post. Retrieved August 4, 2014. (http://www.huffingtonpost.com/2014/04/03/back-alleyabortions_n_5065301.html).

Beasley, E. (2010). Social norms and academic dishonesty. Michigan State University. Master's thesis. Retrieved May 23, 2014 (http://gradworks.umi.com/14/78/1478816.html). 
Beck, K. H., \& Treiman, K. A. (1996). The relationship of social context of drinking, perceived social norms, and parental influence to various drinking patterns of adolescents. Addictive Behaviors 21(5): 633-44. doi: 10.1016/0306-4603(95)00087-9.

Berkowitz, A. D. (2004). The social norms approach: Theory, research, and annotated Bibliography. Retrieved June 1, 2015. (http://www.alanberkowitz.com/articles/social_norms.pdf)

Bhutta, C. B. (2012). Not by the book: Facebook as a sampling frame. Sociological Methods and Research. Published online before print, March 21, 2012. doi: 10.1177/0049124112440795.

Borsari, B., \& Carey, K. B. (2003). Descriptive and injunctive norms in college drinking: A meta-analytic integration. Journal of Studies on Alcohol 64(3): 331-41. doi: http://dx.doi.org/10.15288/jsa.2003.64.331.

Cates, W., Grimes, D. A., \& Schulz, K. F. (2007). The public health impact of legal abortion: 30 years later. Perspectives on Sexual and Reproductive Health 35(1): 25-28. doi: 10.1111/j.1931-2393.2003.tb00081.x

Carter, J. S., Carter, S. K., \& Dodge, J. (2009). Trends in abortion attitudes by race and gender: A reassessment over a four decade period. Journal of Sociological Research 1(1): 1-17. Retrieved July 14, 2012. (http://www.macrothink.org/journal/index.php/jsr/article/view/156). DOI: 10.5296/jsr.v1i1.156.

Center for Disease Control and Prevention. (2013). Abortion surveillance United States, 2010. Retrieved May 21, 2014. (http://www.cdc.gov/mmwr/preview/mmwrhtml/ss6208a1.htm).

Chou, H. G., \& Edge, N. (2011). "They are happier and having better lives than I am": The impact of using facebook on perceptions of others' lives. Cyberpsychology, Behavior, and Social Networking 15(2): 117-21. doi: 10.1089/cyber.2011.0324.

CNN/ORC Poll. 2012. Retrieved April 2, 2014. (http://i2.cdn.turner.com/cnn/2012/images/08/24/rel8a.pdf).

Cockrill, K., \& Nack, A. (2013). "I'm not that type of person": Managing the stigma of having an abortion. Deviant Behavior 34(12): 973-90. doi: 10.1080/01639625.2013.800423.

Cowan, S. K. (2013). Secrets and social influence. Dissertation. UC Berkeley: Sociology \& Demography. Retrieved August 12, 2014. (http://escholarship.org/uc/item/1hf7s08s).

Cialdini, R. B., \& Trost, M. R. (1998). Social influence: Social norms, conformity and compliance. Pp. 151-92 in D. T. Gilbert, S. T. Fiske, and G. Lindzey (Eds.), The handbook of social psychology, vols. 1 and 2 (4th ed.). New York, NY: McGraw-Hill.

Clark, C. (1999). "Gender, correlates, and perceptions of masturbation frequency." Presented at the 1999 Society for the Scientific Study of Sexuality, Midcontinent Region Annual Conference, Madison WI. May 20-23, 1999. 
Couper, M. P. (2011). The future modes of data collection. Public Opinion Quarterly 75(5): 889-908. doi: 10.1093/poq/nfr046

Folkes, V. S. (1988). The availability heuristic and perceived risk. Journal of Consumer Research 15(1): 13-23. doi: 10.1086/209141.

Gilens, M. (1996). Race and poverty in American public misperceptions and the American news media. Public Opinion Quarterly 60(4): 515-41. doi: $10.1086 / 297771$.

Glassner, B. (2010). Culture of fear: Why Americans are afraid of the wrong things - crime, drugs, minorities, teen moms, killer kids, mutant microbes, plane crashes, road rage, and so much more. New York, NY: Basic Books.

Guttmacher Institute. (2012). State facts about unintended pregnancy: Michigan. Retrieved May 21, 2014. (https://www.guttmacher.org/statecenter/unintended-pregnancy/MI.html).

Guttmacher Institute. (2013). Facts on unintended pregnancy in the United States. Retrieved May 21, 2014. (https://www.guttmacher.org/pubs/FBUnintended-Pregnancy-US.html).

Hampton, K. N., Goulet, L. S., Rainie, L., \& Purcell, K. (2011). Social networking sites and our lives: How people's trust, personal relationships, and civic and political involvement are connected to their use of social networking sites and other technologies. Pew Internet \& American Life Project. Retrieved August 7, 2014. (http://www.pewinternet.org/ /media/Files/Reports/2011/PIP\%20$\% 20$ Social\% 20networking\%20sites\%20and\%20our\%20lives.pdf)

Ipsos, M. (2013). Conception statistics, England and Wales. Retrieved May 11, 2014. (http://www.ons.gov.uk/ons/publications/re-referencetables.html?edition=tcm\%3A77-294336)

Jelen, T. G., \& Wilcox, C. (2003). Causes and consequences of public attitudes toward abortion: A review and research agenda. Political Research Quarterly 56(4): 489-500. doi: 10.1177/106591290305600410.

Jones, J. (2009). "Who adopts? Characteristics of women and men who have adopted children. NCHS Data Brief (12): 1-8. Retrieved December 11, 2015. (http://www.cdc.gov/nchs/data/databriefs/db12.htm)

Lambert, T. A., Kahn, A. S., \& Apple, K. J. (2003). Pluralistic ignorance and hooking up. Journal of Sex Research 40(2): 129-33. doi: 10.1080/00224490309552174.

Lawrence, E., Sides, J. (2011). "The consequences of political innumeracy. APSA 2011 Annual Meeting Paper. Retrieved August 12, 2014. (http://www.researchgate.net/publication/228198313_The_Consequences_ of_Political_Innumeracy/file/9c96052d3f74a2493d.pdf).

Maxwell, C. J. C. (2002). Pro-life activists in America: Meaning, motivation, and direct action. Cambridge, UK: Cambridge University Press.

Oskamp, S., \& Schultz, P.W. (2005). Attitudes and opinions. Mahwah, NJ: Lawrence Erlbaum Associates, Inc.

Pazol, K. et al. (2011). CDC abortion surveillance - United States 2008. Morbidity and Mortality Weekly Report, Centers for Disease Control and 
Prevention. Retrieved August 1, 2014.

(http://origin.glb.cdc.gov/Mmwr/preview/mmwrhtml/ss6015a1.htm).

Perkins, H. W. (2003). The social norms approach to preventing school and college age substance abuse: A handbook for educators, counselors, and clinicians. San Francisco, CA: Jossey-Bass.

Perkins, H. W. (2002). Social norms and the prevention of alcohol misuse in collegiate contexts. Journal of Studies on Alcohol and Drugs 14(March): 164-172.

Perkins, H. W., \& Berkowitz, A.D. (1986). Perceiving the community norms of alcohol use among students: Some research implications for campus alcohol and other drug use on college campuses. International Journal of the Addictions 21(9/10): 961-76.

Pew Forum on Religion \& Public Life. (2008). U.S. religious landscape survey. Retrieved August 1, 2014. (http://www.pewforum.org/2008/06/23/usreligious-landscape-survey-resources/).

Pew Research Center for the People and the Press. (2012). The complicated politics of abortion. Retrieved April 29, 2014. (http://www.peoplepress.org/2012/08/22/the-complicated-politics-of-abortion/).

Pinker, S. (2012). The better angels of our nature: Why violence has declined (Reprint edition). New York, NY: Penguin Books.

Pinkerton, S. D., Bogart, L. M., Cecil, H., \& Abramson, P. R. (2003). Factors associated with masturbation in a collegiate sample. Journal of Psychology \& Human Sexuality 14(2-3): 103-21. doi: 10.1300/J056v14n02_07.

PolitiFact. n.d. "Rick Santorum says one of every three pregnancies ends in an abortion.” Retrieved May 22, 2014. (http://www.politifact.com/truth-ometer/statements/2011/mar/31/rick-santorum/rick-santorum-says-oneevery-three-pregnancies-end/).

Pollitt, K. (2014). Pro: Reclaiming abortion rights. New York, NY: Picador.

Prentice, D. A., \& Miller, D. T. (1993). Pluralistic ignorance and alcohol use on campus: Some consequences of misperceiving the social norm. Journal of Personality and Social Psychology 64(2): 243-56. doi: 10.1037/00223514.64.2.243.

ProCon.org. (2011, April 4). U.S. religious views on abortion. Retrieved from http://abortion.procon.org/view.resource.php? resourceID $=004208$

Rimal, R. N., \& Real, K. (2003). Understanding the influence of perceived norms on behaviors. Communication Theory 13(2): 184-203. doi: 10.1111/j.1468-2885.2003.tb00288.x.

Ross, L., Greene, D., \& House, P. (1977). The "false consensus effect": An egocentric bias in social perception and attribution processes. Journal of Experimental Social Psychology 13(3): 279-301.

Saad, L. (2012). Abortion is threshold issue for one in six U.S. voters: Nearly as many single-issue abortion voters are pro-choice as pro-life. Retrieved May 5, 2014. (http://www.gallup.com/poll/157886/abortion-thresholdissue-one-six-voters.aspx) 
Saad, L. (2013). Majority of Americans still support Roe v. Wade decision. Retrieved May 5, 2014. (http://www.gallup.com/poll/160058/majorityamericans-support-roe-wade-decision.aspx).

Salmon, C. T., \& Neuwirth, K. (1990). Perceptions of opinion climes and willingness to discuss the issue of abortion. Journalism and Mass Communication Quarterly 67(3): 567-577.

Scholly, K., Katz, A. R., Gascoigne, J., \& Holck, P. S. (2005). Using social norms theory to explain perceptions and sexual health behaviors of undergraduate college students: An exploratory study. Journal of American College Health 53(4): 159-66. doi: 10.3200/JACH.53.4.159166

Schultz, P. W., Nolan, J. M., Cialdini, R. B., Goldstein, N. J., \& Griskevicius, V. (2007). The constructive, destructive, and reconstructive power of social norms." Psychological Science 18(5): 429-34. doi: 10.1111/j.14679280.2007.01917.x.

Shaw, D. (2010). Abortion and human rights." Best Practice \& Research Clinical Obstetrics \& Gynaecology 24(5): 633-46. doi: 10.1016/j.bpobgyn.2010.02.009.

Shellenberg, K. M., et al. (2011). Social stigma and disclosure about induced abortion: Results from an exploratory study. Global Public Health 6(sup1): S111-S125. doi: 10.1080/17441692.2011.594072.

Singh, S., Remez, L., \& Tartaglione, A. (Eds.) (2011). Methodologies for estimating abortion incidence and abortion-related morbidity: A review. Guttmacher Institute. Retrieved August 1, 2014. (http://www.guttmacher.org/pubs/compilations/IUSSP/abortionmethodology.html)

Smith, T. W. \& May, J. S. (2013). Trends in public attitudes towards abortion. General Social Survey 2012 Final Report. Retrieved May 11, 2014. (http://www.norc.org/PDFs/GSS\%20Reports/Trends\%20in\%20Attitudes $\% 20$ About\%20Abortion_Final.pdf)

Tversky, A., \& Kahneman, D. (1974). Judgment under uncertainty: Heuristics and biases. Science 185(4157): 1124-31. doi: 10.1126/science.185.4157.1124. . (1973). Availability: A heuristic for judging frequency and probability. Cognitive Psychology 5(2): 207-32. doi: 10.1016/0010-0285(73)90033-9.

Washington Post/Kaiser Family Foundation Poll. (2012). Retrieved April 2, 2014. (http://www.washingtonpost.com/politics/polling/abortion-illegal-illegalthink/2012/08/23/aa56d0aa-e984-11e1-9739-eef99c5fb285_page.html).

Wilcox, C., \& Gomez, L. (1990). "The Christian Right and the Pro-life movement: An analysis of the sources of political support." Review of Religious Research 31(4): 380-389. doi: 10.2307/3511563 